\title{
Experimental Study and Finite Element Analysis of Hysteretic Behavior of End-plate Connection Semi-Rigid Space Steel Frames
}

\author{
Wang Tao ${ }^{1,2, *}$, Wang Zhan ${ }^{1,2}$ and Wang Junqi ${ }^{1,2}$ \\ ${ }^{1}$ State Key Laboratory of Subtropical Building Science, South China University of Technology, Guangzhou 510640, \\ China \\ ${ }^{2}$ School of Civil Engineering and Transportation, South China University of Technology, Guangzhou 510640, China
}

\begin{abstract}
To investigate the seismic behavior of end-plate connection semi-rigid space steel frames, three $1 / 4$-scale specimens were tested under cyclic load. Finite element analysis which took initial geometric imperfections into consideration was also conducted, and the results conform to experimental results. The failure modes, hysteretic behavior, deformation capacity and energy-dissipation capacity of the end-plate connection semi-rigid space steel frame have been explicated in this paper. The investigation in this paper indicates that: (1) the end-plate connection semi-rigid space steel frames exhibit full hysteretic loops under horizontal cyclic load and have good ductility as well, indicating that this kind of frames can satisfy the deformation demand in strong earthquakes. (2) Plastic hinges formed at beam ends, and the stress and deformation amplitudes of joint-panels were smaller than those of column base and beam ends. It shows that this kind of frames satisfy the design principle "strong column weak beam, strong joint weak component".
\end{abstract}

Keywords: Semi-rigid space steel frames, end-plate connection, hysteretic behavior experiment, FEM analysis, ductility.

\section{INTRODUCTION}

Widespread and unanticipated failures in welded steel beam-column connections were observed in both the 1994 Northridge Earthquake and the 1995 Hyogoken-Nanbu Earthquake [1-3]. Plenty of investigations and researches indicate that the beam-column connection failure was caused by the brittle fracture of welds. The seismic behavior of semi-rigid connections, which exhibit better ductility than welded connections, has been widely studied since the Northridge Earthquake. A lot of experimental and theoretical studies on the seismic performance of semi-rigid connections were conducted, and some useful conclusions have been attained. However, the seismic behavior of semi-rigid steel frames has not yet been systematically studied.

Previous studies show that semi-rigid steel frames exhibited obviously different performance and failure modes compared with rigid steel frames under dynamic actions [4-7]. It is expected that studies and analysis on the dynamic behavior of semi-rigid steel frames will further promote the application of this kind of structures in seismic regions. Hence the studies on the seismic behavior of semi-rigid steel frames under cyclic loading will be of high value, which also correspond with the requirement of the development trend of steel structure.

\footnotetext{
*Address correspondence to this author at the State Key Laboratory of Subtropical Architecture Science, Department of Civil Engineering and Transportation, South China University of Technology, Guangzhou 510640, China; Tel: (+86)15813393663; Fax: (+86)020-87113421;

E-mail: wangtao195046@126.com
}

This paper presents experimental study on the seismic behavior of semi-rigid space steel frames with end plate connections. FEM models taking the effect of initial geometric imperfections into account were also developed using ABAQUS. By comparing the experimental results and FEM analysis, several conclusions in terms of the hysteretic behavior, ductility, and bearing capacity of this kind of frames are obtained.

\section{TEST PROGRAM}

\subsection{Structure Model}

Three structure models of the semi-rigid steel frames with reduced scale of $1 / 4$ were fabricated based on the "Code for Design of Steel Structures of China" [8]. The size of the models was determined, according to the commonly used story height, the spatial arrangement of columns, the crosssectional dimensions of beams and columns in actual frame structures, and also the configuration of hydraulic jack. Two of the models were designed to be single-story frames, denoted as KJ1 and KJ2 respectively; while the other was designed to be a two-story frame, denoted as KJ3. The geometrical dimensions of the three models are shown in Fig. (1) and Fig. (2). The column spacing in $\mathrm{X}$ and $\mathrm{Y}$ directions is $1.5 \mathrm{~m}$; and the story height is $0.8 \mathrm{~m}$. All columns and beams were fabricated by H-shaped steel. Extended end plate connections were used in these experimental frames with frictional high-strength bolts of grade 10.9, which were pretensioned to the value of $100 \mathrm{kN}$ as prescribed in the China Design Code (GB50017-2003) [8]. The details of bolts are shown in Fig. (3). Floor slabs were substituted by $10 \mathrm{~mm}-$ thick steel plates which were welded to structure members. Two factors were taken into account in determining the thickness of steel plates, the first one is that $10 \mathrm{~mm}$-thick 


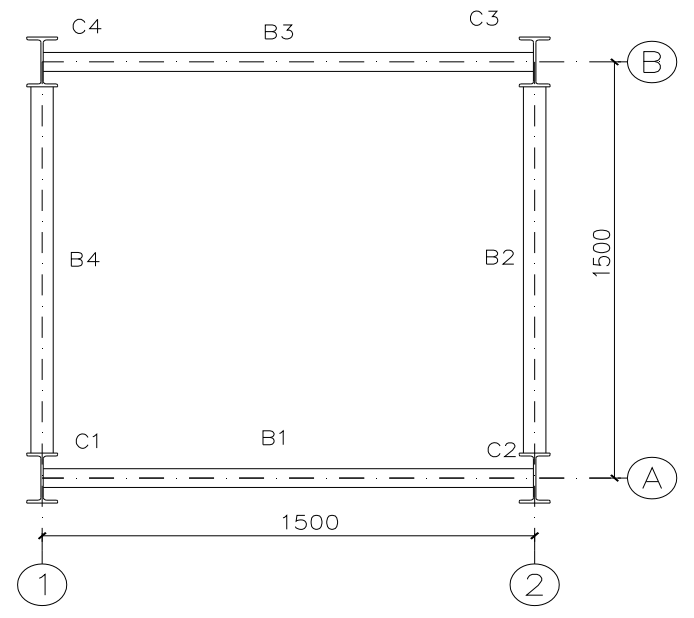

Fig. (1). Plan view of the specimens ( $\mathrm{mm})$.

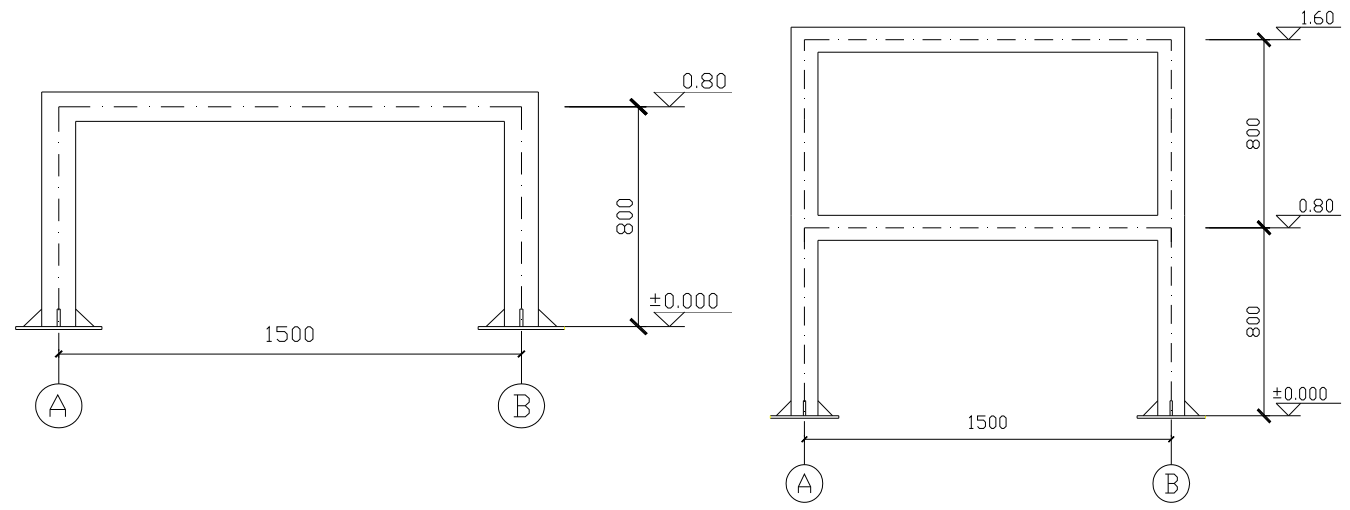

(a) Single-story frame solid plan

(b) Two-story frame plan

Fig. (2). Elevation view of specimens (mm).

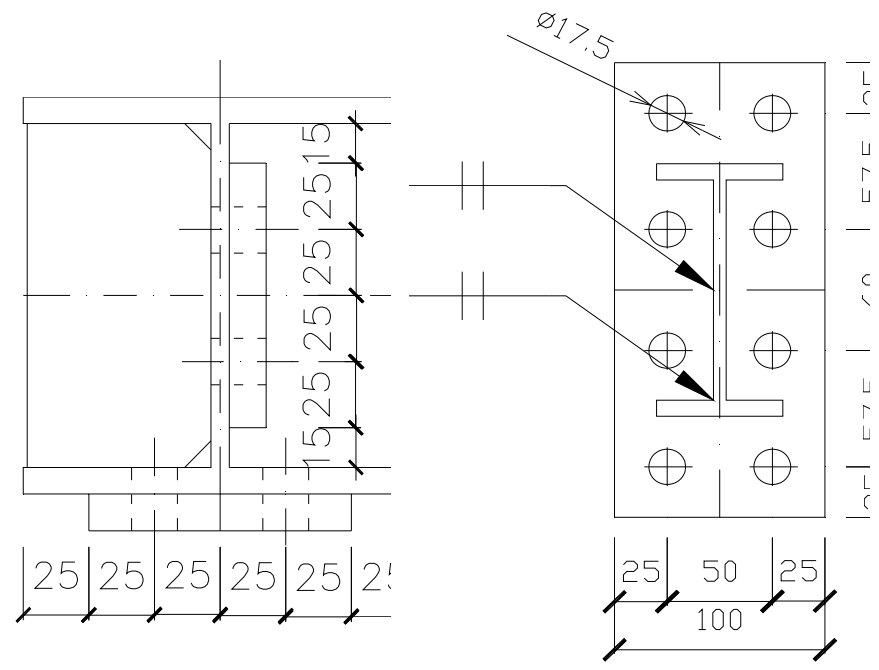

Fig. (3). Beam-to-column connections (mm).

steel plates can offer sufficient plane stiffness as the real composite floor slab; and the second one is that $10 \mathrm{~mm}$-thick steel plates are strong enough to suffer the vertical load. The floor arrangement is shown in Fig. (4). The rigid column bases were welded to ground beams. Stiffeners were set around both the column flange and web to increase the flexural rigidity, as shown in Fig. (5). Table 1 illustrates the configuration of experimental frame members, in which $h, b, t_{w}$, $t_{f}$ stand for the section height, the section width, the web thickness, and the flange thickness respectively. 
Table 1. Main Parameters of the Specimens (mm)

\begin{tabular}{|c|c|c|c|c|c|c|}
\hline Frame & $\begin{array}{l}\text { Column Section } \\
\left(h \times b \times t_{w} \times t_{f}\right)\end{array}$ & $\begin{array}{c}\text { Beam Section } \\
\left(h \times b \times t_{w} \times t_{f}\right)\end{array}$ & $\begin{array}{c}\text { Foundation Beam } \\
\left(h \times b \times t_{w} \times t_{f}\right)\end{array}$ & $\begin{array}{c}\text { Loading Beam } \\
\left(h \times b \times t_{w} \times t_{f}\right)\end{array}$ & $\begin{array}{l}\text { End Plate } \\
\text { Thickness }\end{array}$ & $\begin{array}{l}\text { Bolt Di- } \\
\text { ameter }\end{array}$ \\
\hline $\mathrm{KJ} 1, \mathrm{KJ} 2, \mathrm{KJ} 3$ & $\mathrm{H} 150 \times 150 \times 7 \times 10$ & $\mathrm{H} 150 \times 75 \times 5 \times 7$ & $\mathrm{H} 244 \times 175 \times 7 \times 11$ & $\mathrm{H} 300 \times 150 \times 6.5 \times 9$ & 14 & 16 \\
\hline
\end{tabular}

\subsection{Test Setup}

The test setups are illustrated in Fig. (6). The horizontal load was applied to each floor by two hydraulic jacks 7 and 7 ', with a capacity of $1000 \mathrm{kN}$. The loading points were located at the center of the loading beams which was designed to transfer the load from the hydraulic jacks to the structures. $\mathrm{KJ} 1$ and $\mathrm{KJ} 3$ were loaded at the strong axis direction while KJ2 was loaded at the weak axis direction. Cyclic load was applied to the models by one of the hydraulic jacks since the hydraulic jacks with push force only were adopted in the tests. Foundation beams were horizontally fixed by screw jack 8 . The weight blocks with $2000 \mathrm{Kg}$ were placed on each floor of the frame. The test photos are shown in Fig. (7).

\subsection{Loading Protocol}

The loading protocol is presented in Fig. (8). The load controlled mode was adopted before yielding of the specimens with the stepwise incremental cyclic loading at 1/10 of the yield load (one cycle each). The yield load and yield displacement were determined based on the maximum strain and load-displacement curves. It was then followed by a displacement controlled mode after yielding with the stepwise incremental cyclic loading amplitudes based on the yield displacement as shown in Fig. (6) (two cycles each), until the specimens failed. Note that the same loading amplitudes were applied at each floor of specimen $\mathrm{KJ} 3$.

\subsection{Test Instrumentation}

The test instrumentation included: (1)Horizontal load; (2)Displacements at each floor and column base, (see Fig. 9); (3)strain amplitudes at the column base, the beam ends and the joint region; (4) The inter-story drift of the specimens could then be obtained based on Eqs. (1) and (2);

Displacement at the first floor:

$U_{1}=\frac{\left(D_{1}-D_{0}\right)+\left(D_{1}{ }^{\prime}-D_{0}{ }^{\prime}\right)}{2}$

Displacement at the second floor:

$U_{2}=\frac{\left(D_{2}-D_{0}\right)+\left(D_{2}^{\prime}-D_{0}{ }^{\prime}\right)}{2}$

(5) Record of the failure process of experimental frames.

\section{FINITE ELEMENT MODELS}

\subsection{Element Selection and Material Constitutive Model}

The ABAQUS6.11 was used to develop the finite element models. The 8-node linear reduced integral elements C3D8R were defined for all the structural members. Multi- linear isotropic hardening model was adopted for beams, columns and end plates, and bilinear isotropic hardening model was adopted for bolts. Mises yield criterion and associated flow rule were also applied. The constitutive model of steel obtained from the tests is shown in Table 2; the constitutive model of bolts applied in this paper was defined based on [9], which is shown in Table 3. Prestressing force of all the bolts and the friction coefficient of all contact faces was $100 \mathrm{kN}$ and $0.45[8,9]$. The slab-to-beam connections were modeled using the node-to-node contact method, and the six DOFs of column bases were all fixed in the numerical models.

\subsection{Key Steps of Finite Element Analysis}

(1) Buckling analysis: the first 20 buckling modes of the

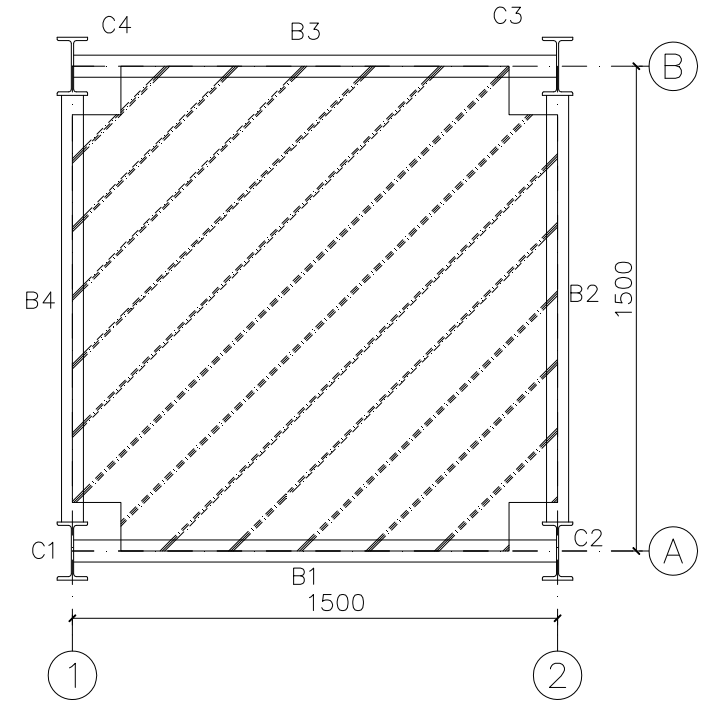

Fig. (4). Plan view of floor slab arrangement (mm).
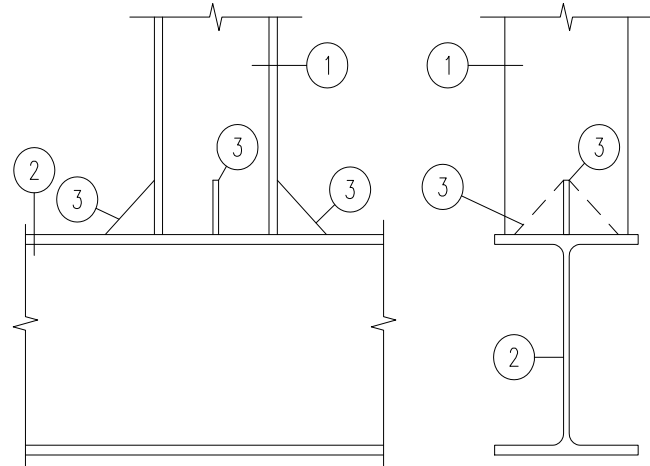

Fig. (5). Column base joints (mm) 
Table 2. Main Material Properties of the Test Specimens

\begin{tabular}{|c|c|c|c|c|}
\hline Thickness $(\mathbf{m m})$ & Yield strength $\boldsymbol{f}_{\mathbf{y}}(\mathbf{M P a})$ & Ultimate Strength $\boldsymbol{f}_{\boldsymbol{u}}(\mathbf{M P a})$ & Elastic Modulus $\boldsymbol{E ( G P a )}$ & Elongation $\Delta \boldsymbol{L} / \boldsymbol{L}(\mathbf{\%})$ \\
\hline \hline 5 & 283.2 & 418.1 & 199.3 & 20.6 \\
\hline 7 & 281.6 & 409.3 & 198.0 & 19.7 \\
\hline 9 & 280.0 & 410.8 & 194.9 & 21.8 \\
\hline 10 & 279.3 & 405.1 & 196.6 & 24.9 \\
\hline 11 & 274.9 & 401.1 & 191.1 & 23.1 \\
\hline 14 & 270.0 & 397.5 & 186.3 & 24.8 \\
\hline
\end{tabular}

Table 3. Properties of High Strength Bolts

\begin{tabular}{|c|c|c|c|c|}
\hline Material & Yield Strength $\boldsymbol{f}_{\boldsymbol{y}}(\mathbf{M P a})$ & Ultimate Strength $\boldsymbol{f}_{\boldsymbol{u}}(\mathbf{M P a})$ & Yield Strain $\varepsilon_{\boldsymbol{y}}(\%)$ & Ultimate Strain $\varepsilon_{\boldsymbol{u}}(\%)$ \\
\hline \hline High strength bolt & 940 & 1130 & 0.456 & 10 \\
\hline
\end{tabular}

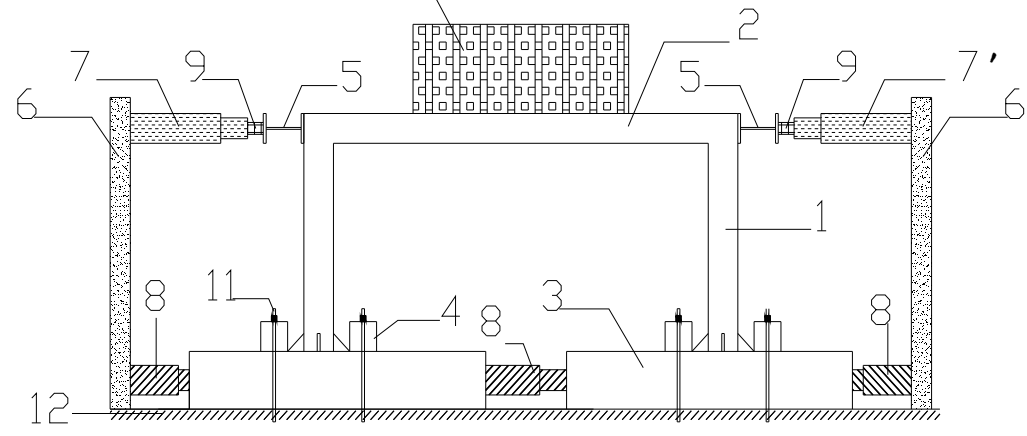

Fig. (6). Test setup. 1.Column 2.Beam 3.Foundation beam 4.Fixing beam 5.Distributing girder 6.Reacting wall 7.Hydraulic jack(loading) 8.Screw jack (horizontally fixed) 9.Load cell 10.Mass blocks 11.Fixed bolt 12.Rigid ground.

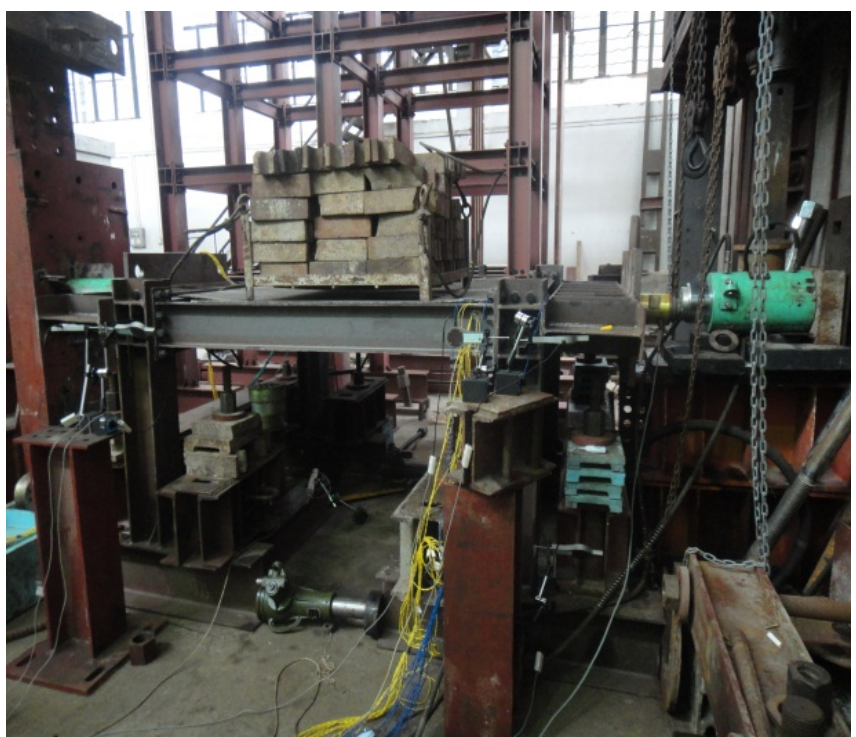

(a) Single-storey frame

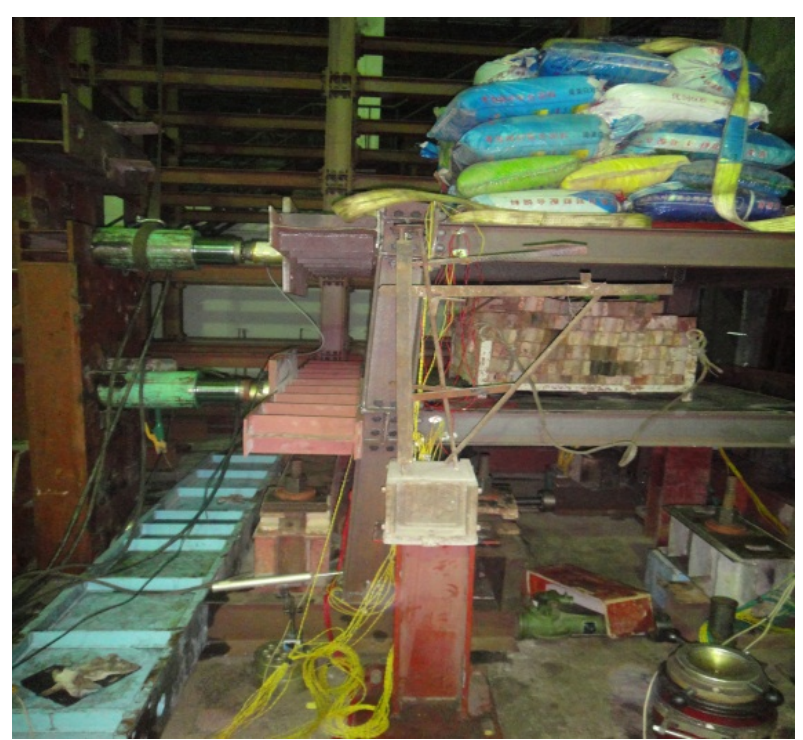

(b) Two-storey frame

Fig. (7). Test photos.

structures were obtained.

(2) Introducing initial geometric imperfections: the bucking modes that correspond with the failure modes of the test specimens were adopted for introducing the initial geometric imperfections into the beams with the amplitude of $1 / 1000$ of the beam spacing for each mode [10]. 


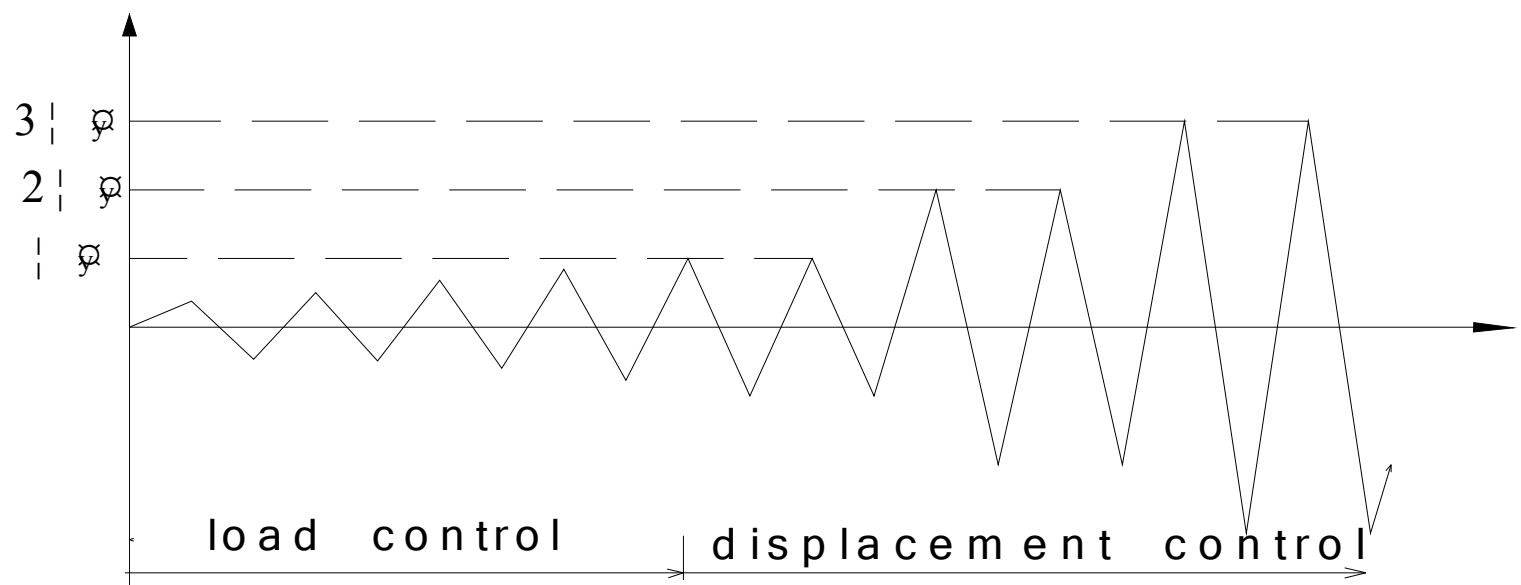

Fig. (8). Loading protocol.

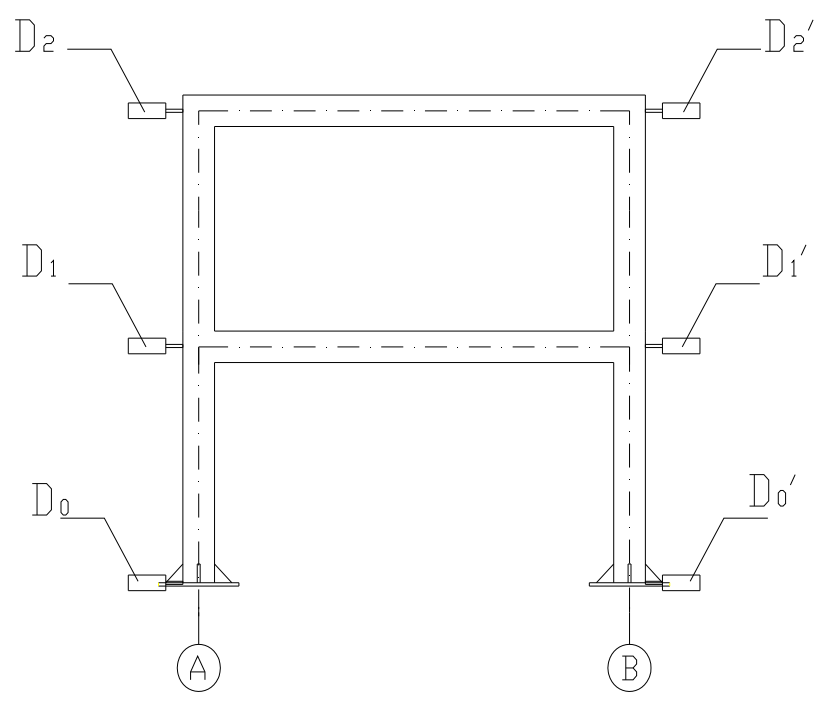

Fig. (9). Arrangement of displacement transducers.

(3) Non-linear analysis of structure: monotonic loading was imposed on the FEM models only and the loading points and boundary conditions were modeled based on the test specimens. Geometrical nonlinearity was also considered in the FEM analysis.

\section{EXPERIMENTAL RESULTS}

\subsection{Hysteretic Behavior}

Fig. (10) shows the lateral force versus the horizontal displacement relationship for the test specimens. $P$ and $\Delta$ represents the total lateral load applied on the specimens and the horizontal displacement at the top floor, respectively.

It shows that the structures remain elastic before yielding. The area of hysteretic loops gradually increased and residual deformations were observed with the increase of displacement after yielding. Also, the lateral stiffness decreased with the increase of the lateral loads. No pinch effect was ob- served for the specimens, indicating that the specimens exhibited good energy dissipation capacity.

\subsection{Lateral Load-displacement Response Envelope}

Fig. (11). shows the comparison between the lateral loaddisplacement response envelope, obtained from the tests, and the numeral results obtained from FEM push-over analysis. It indicates that the FEM curves correspond well with the test results, which validates the effectiveness of FEM analysis. However, it is found that the yielding strength and ultimate strength obtained from FEM analysis are higher than the test results, which can be attributed to the following reasons:

(1) The foundations of the specimens were not perfectly rigid as we assumed in the FEM analysis;

(2) FEM analysis only took geometric imperfections into account, while material imperfections especially weld imperfections were neglected. 


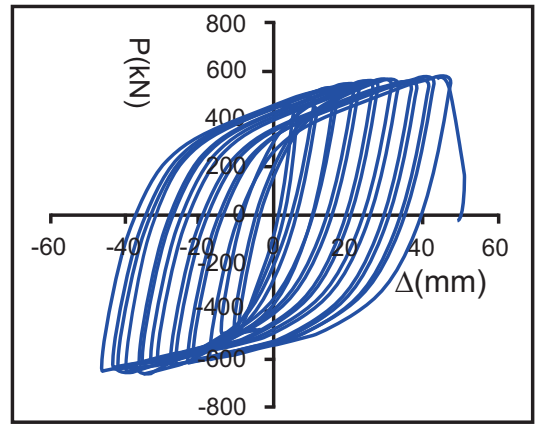

(a)KJ1

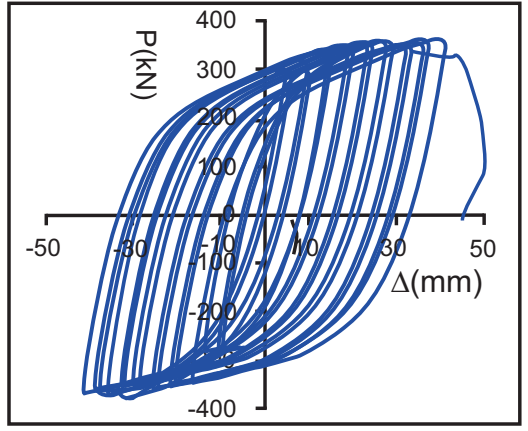

(b)KJ2

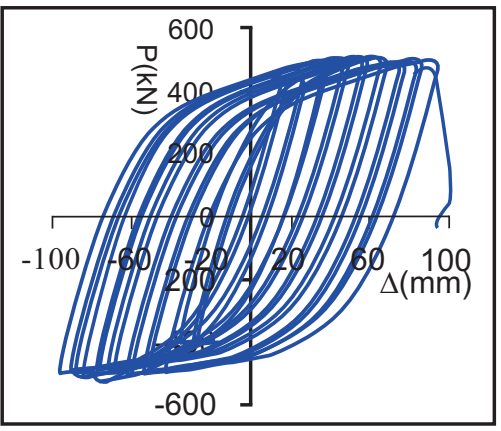

(c) $\mathrm{KJ} 3$

Fig. (10). Hysteretic response curves.

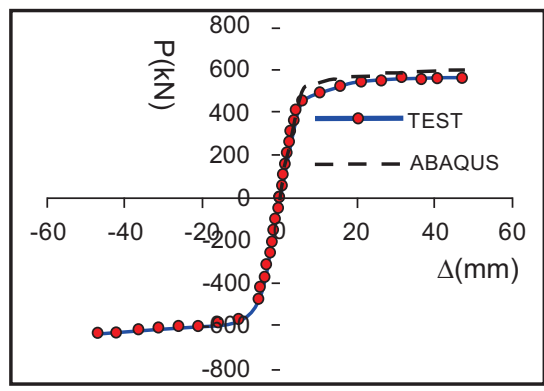

(a) KJ1

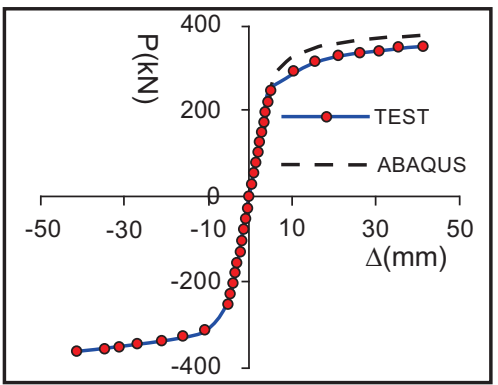

(b) $\mathrm{KJ} 2$

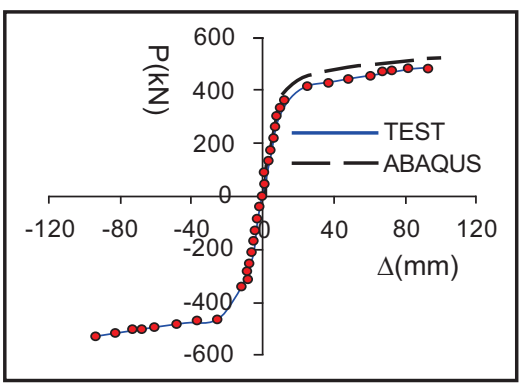

(c) $\mathrm{KJ} 3$

Fig. (11). Lateral load-displacement response envelope.

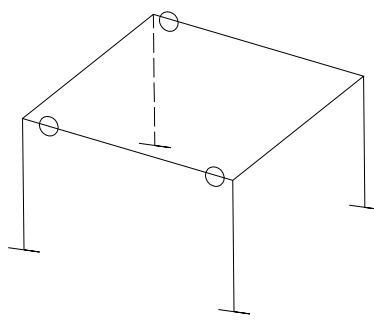

(a) $5 \mathrm{~mm}$

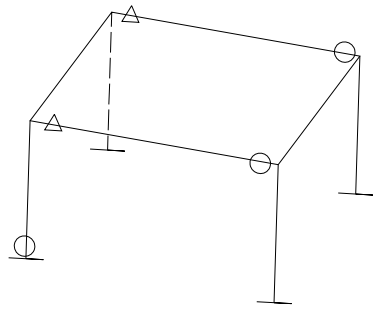

(b) $15 \mathrm{~mm}$

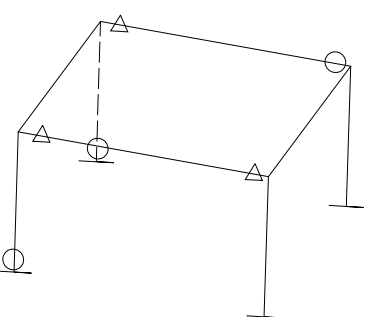

(c) $30 \mathrm{~mm}$

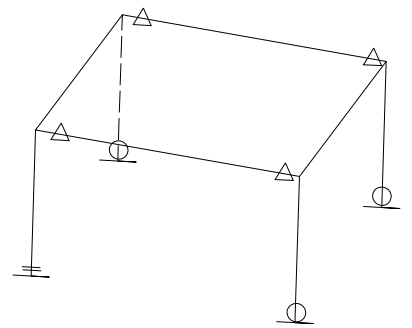

(d) $45 \mathrm{~mm}$

Fig. (12). Failure process for KJ1.

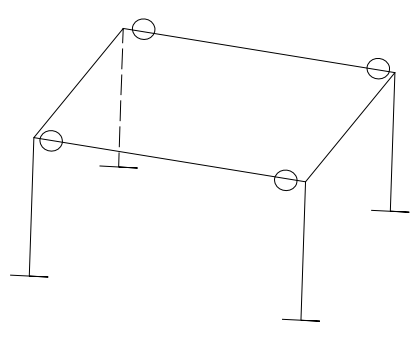

(a) $5 \mathrm{~mm}$

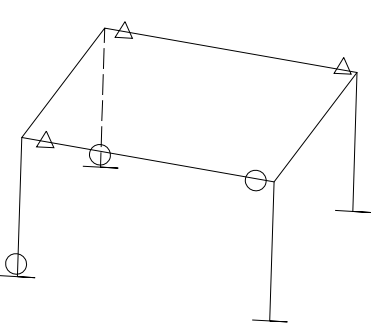

(b) $15 \mathrm{~mm}$

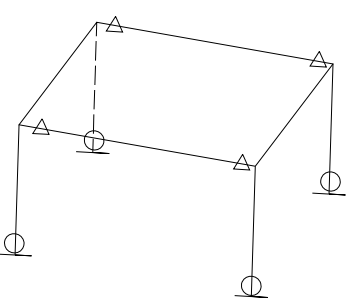

(c) $30 \mathrm{~mm}$

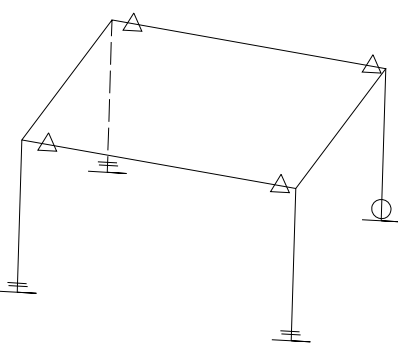

(d) $40 \mathrm{~mm}$

Fig. (13). Failure process for KJ2.

\subsection{Description and Analysis of Failure Modes}

Figs. (12, 13 and 14) show the failure process of the three test specimens at the representative lateral displacement amplitudes. In these figures, the symbol " $\bigcirc$ " represents the locations for initiate yielding of the structural members which could be determined by strain values; the symbol " $\Delta$ " represents the occurrence of local buckling, which can be determined from the tests; the symbol "=" represents the location for weld fracture, which can be determined from the tests.

The Failure process can be summarized as follows: 


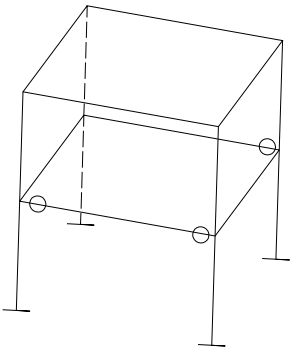

(a) $10 \mathrm{~mm}$

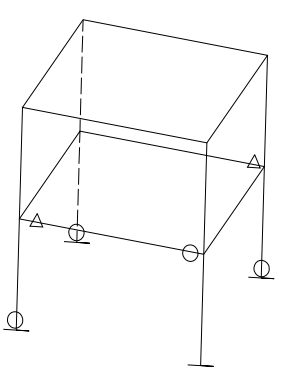

(b) $35 \mathrm{~mm}$

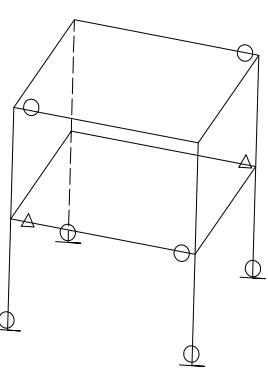

(c) $60 \mathrm{~mm}$

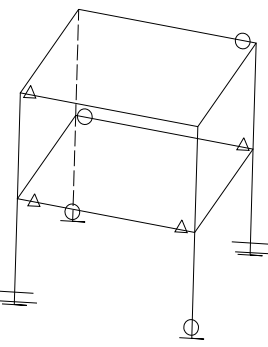

(d) $90 \mathrm{~mm}$

Fig. (14). Failure process for KJ3.

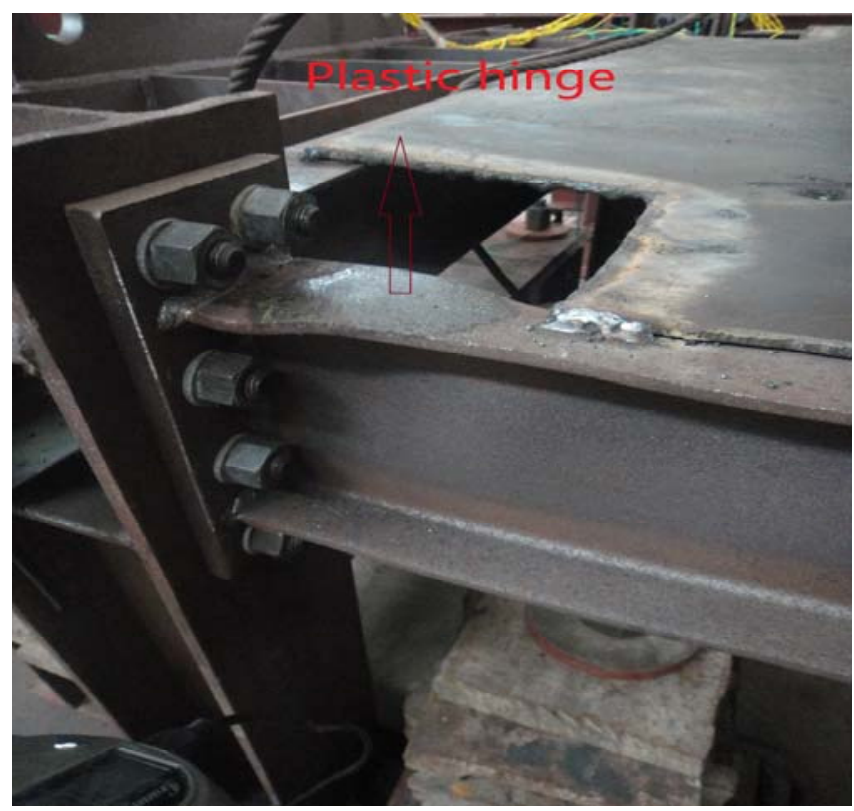

(a) Test observation

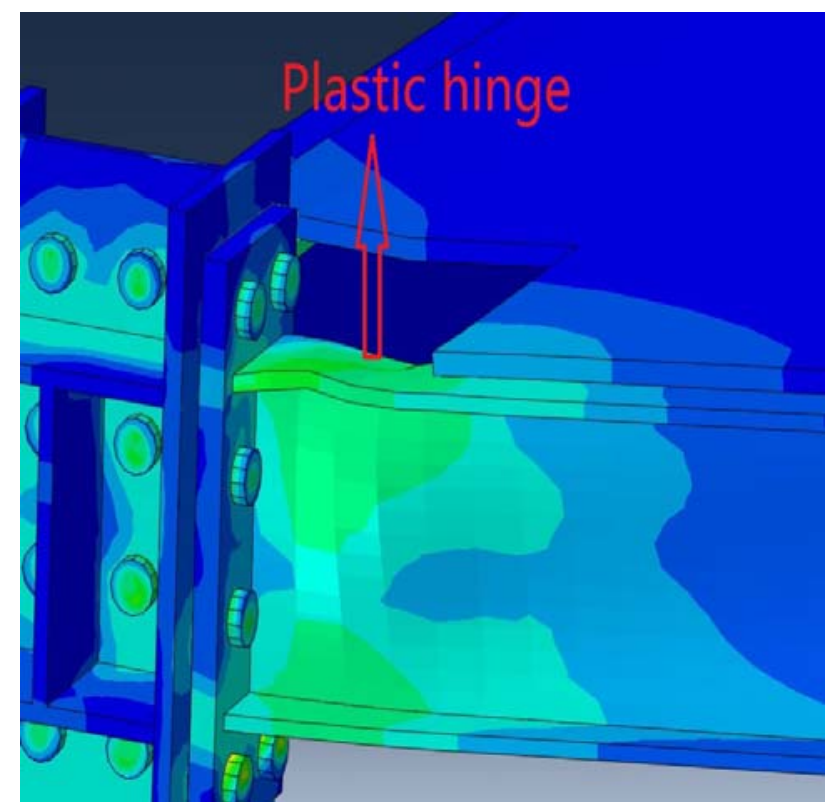

(b) FEM analysis

Fig. (15). Plastic hinge developed at the beam ends.

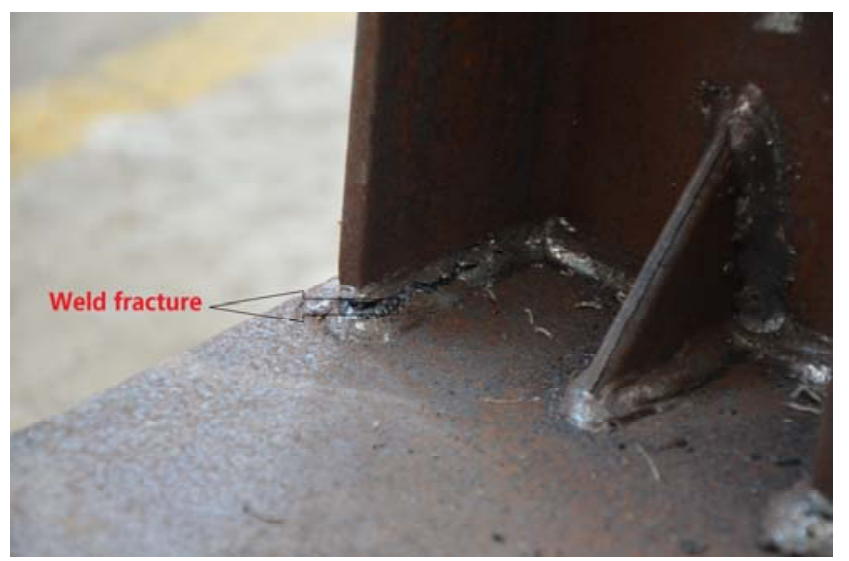

(a) Weak axis direction

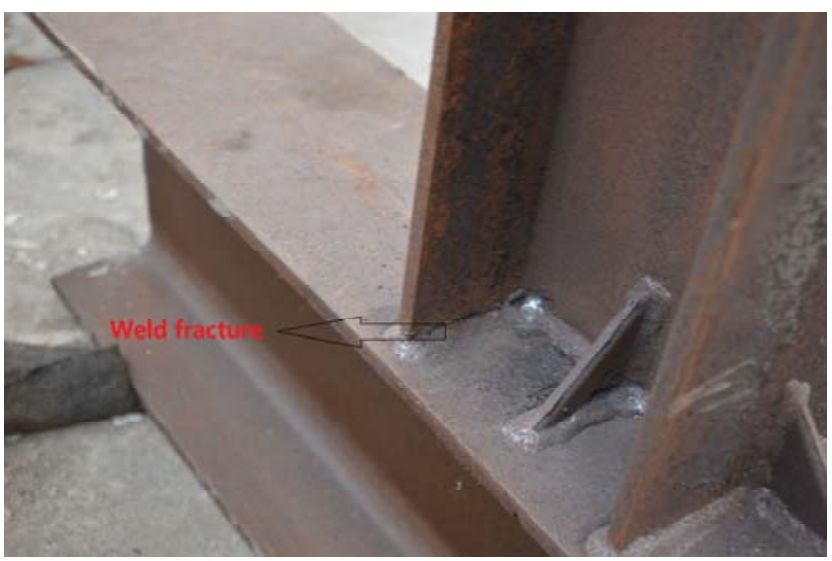

(b) Strong axis direction

Fig. (16). Weld fracture.

(1) Initial yielding was observed at the beam ends, which led to the nonlinearity observed for the P- $\Delta$ curves and the decrease of lateral stiffness;

(2) Local buckling occurred at the end of beam flange and web indicating the development of plastic hinge at the beam ends (see Fig. 15); 


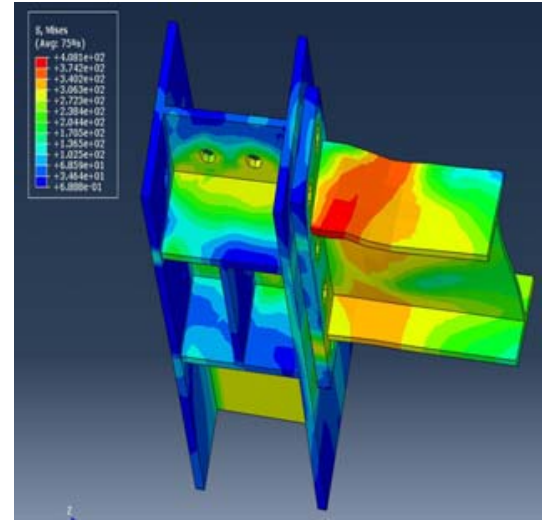

(a) KJ1

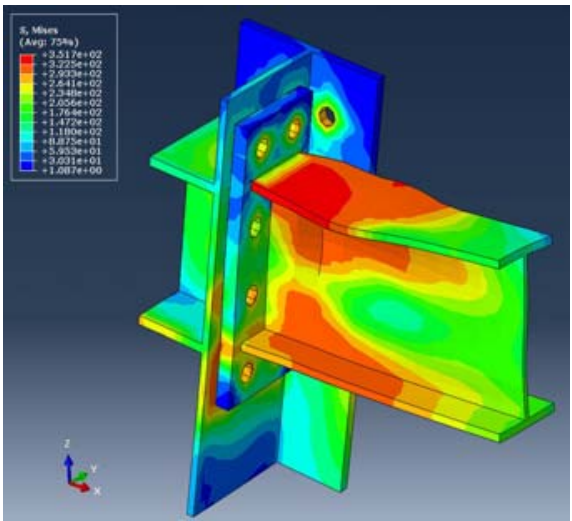

(b) $\mathrm{KJ} 2$

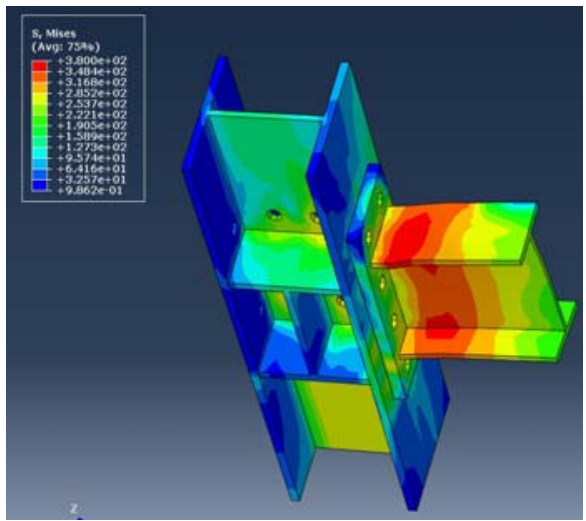

(c) $\mathrm{KJ} 3$

Fig. (17). Mises stress distribution at joint-panels.

Table 4. Key Load and Displacement Values of the Specimens

\begin{tabular}{|c|c|c|c|c|c|c|c|c|c|}
\hline \multirow{2}{*}{ Specimen No. } & \multirow{2}{*}{ Data Source } & \multicolumn{2}{|c|}{ Yielding Point(+) } & \multicolumn{2}{|c|}{ Yielding Point(-) } & \multicolumn{2}{|c|}{ Ultimate Point(+) } & \multicolumn{2}{|c|}{ Ultimate Point(-) } \\
\hline & & $P_{\mathrm{y}}^{+}(\mathrm{kN})$ & $\Delta_{\mathrm{y}}^{+}(\mathrm{mm})$ & $P_{\mathrm{y}}^{-}(\mathrm{kN})$ & $\Delta_{\mathrm{y}}^{-}(\mathrm{mm})$ & $P_{\mathrm{u}}^{+}(\mathrm{kN})$ & $\Delta_{\mathrm{u}}^{+}(\mathbf{m m})$ & $P_{\mathrm{u}}^{-}(\mathbf{k N})$ & $\Delta_{\mathrm{u}}^{-}(\mathrm{mm})$ \\
\hline \multirow{2}{*}{$\mathrm{KJ} 1$} & Test & 444 & 5.43 & -471 & -5.08 & 566 & 47.57 & -609 & -47.03 \\
\hline & ABAQUS & 493 & 5.34 & - & - & 602 & 46.86 & - & - \\
\hline \multirow{2}{*}{$\mathrm{KJ} 2$} & Test & 246 & 5.00 & -246 & -5.00 & 352 & 41.40 & -363 & -41.54 \\
\hline & ABAQUS & 263 & 5.24 & - & - & 377 & 41.20 & - & - \\
\hline \multirow{2}{*}{$\mathrm{KJ} 3$} & Test & 349 & 10.76 & -341 & -10.71 & 482 & 93.77 & -532 & -93.55 \\
\hline & ABAQUS & 378 & 10.78 & - & - & 522 & 98.29 & - & - \\
\hline
\end{tabular}

(3) Buckling at the column base was then observed with significant increase of plastic deformation for the specimens and hence the tangent stiffness of the P- $\Delta$ curves after yielding became significantly small;

(4) The specimens finally failed by the weld fracture observed for the column base (see Fig. 16).

According to the FEM analysis, it is found that the Mises stress value and deformations at the panel end plates, column flange and column web are much smaller than those at the beam ends (see Fig. 17). Also, the strain amplitudes for the panels are smaller than those at the end of beams and column bases with a maximum strain value of $1.35 \mathrm{E}-3$. It indicates that the semi-rigid steel frames using end-plate connections with proper design could satisfy the design principle of "strong column weak beam and strong joint weak component".

According to the above analysis, the yielding of the end of beams occurred before the yielding of column base, which also contributes to the experimental structure's good capacity of energy dissipation.

\subsection{Analysis of Ductility and Energy Dissipation}

Ductility coefficient $\mu$ is used to quantify the deformability capability of the frames, which can be given by:
$\mu=\frac{\left|\Delta_{u}{ }^{+}\right|+\left|\Delta_{u}{ }^{-}\right|}{\left|\Delta_{y}{ }^{+}\right|+\left|\Delta_{y}{ }^{-}\right|}$

$\Delta_{\mathrm{u}}{ }^{+}, \Delta_{\mathrm{u}}{ }^{-}$represent the ultimate displacement in the positive and negative directions, respectively [11]. Energy dissipation coefficient was adopted to evaluate the capacity of energy dissipation which was calculated through the method mentioned in references [11]. The key load and displacement values and the main performance parameters of the specimens are shown in Tables $\mathbf{4}$ and 5, respectively.

According to Table 4 and Table 5, some key results can be obtained as follows:

(1) Ductility coefficient $\mu$ of all the specimens are larger than 8 , and the ultimate inter-story displacement angles fall between 1/19 1/16, which indicates that the semi-rigid steel frames can underwent large deformation without decline of ultimate bearing capacity. Also, the maximum deformation capacity of the specimens were much larger than the inter-story drift limit specified in the seismic design code of China [12], which shows that the semi-rigid steel space frames using end-plate connections exhibited good ductility and their deformability satisfy the ductile demand under strong earthquakes.

(2) The energy dissipation coefficients of the specimens fall between 2.40 2.67, and no apparent pinch effect was ob- 
Table 5. Main Performance Parameters of the Specimens

\begin{tabular}{|c|c|c|c|c|c|c|}
\hline \multirow{2}{*}{ Number } & Data Resource & $\boldsymbol{\mu}$ & $\boldsymbol{P}_{\boldsymbol{u}} / \boldsymbol{P}_{\boldsymbol{y}}$ & $\begin{array}{c}\text { Energy Dissipation Coeffi- } \\
\text { cient } \boldsymbol{E}\end{array}$ & $\begin{array}{c}\text { Ultimate Inter-story Dis- } \\
\text { placement Angle } \boldsymbol{\theta}=\boldsymbol{\Delta}_{\boldsymbol{u}} / \boldsymbol{H}\end{array}$ & $\begin{array}{c}\text { Elastic Inter-story Lateral } \\
\text { Stiffness } \boldsymbol{K}_{\boldsymbol{e}}(\boldsymbol{k} \boldsymbol{N} / \boldsymbol{m} \boldsymbol{m})\end{array}$ \\
\hline \hline \multirow{2}{*}{ KJ1 } & Experimental & 9.00 & 1.28 & 2.67 & $1 / 17$ & 97.75 \\
\cline { 2 - 8 } & ABAQUS & 8.77 & 1.22 & - & $1 / 17$ & $1 / 19$ \\
\hline \multirow{2}{*}{ KJ2 } & Experimental & 8.29 & 1.45 & 2.40 & $1 / 19$ & 58.56 \\
\cline { 2 - 8 } & ABAQUS & 7.86 & 1.43 & - & $1 / 17$ & 55.72 \\
\hline \multirow{2}{*}{ KJ3 } & Experimental & 8.72 & 1.47 & 2.54 & $1 / 16$ & 84.79 \\
\cline { 2 - 7 } & ABAQUS & 9.04 & 1.38 & - & & 83.20 \\
\hline
\end{tabular}

served in the P- $\Delta$ curves (see Fig. 10), indicating that the semi-rigid steel space frames exhibited excellent energy dissipation capacity.

(3) The lateral stiffness of $\mathrm{KJ} 2$ in the weak axis direction is found to be obviously smaller than that of $\mathrm{KJ} 1$ and $\mathrm{KJ} 3$ in the strong axis direction, while the other parameters are basically comparable among the three specimens. Therefore, it is recommended that braces be provided in the weak axis direction of the semi-rigid steel space frames using end-plate connections to balance the lateral stiffness in both strong and weak axis directions of the structures.

\section{CONCLUSIONS}

The seismic behavior of three semi-rigid steel space frames using end-plate connections was investigated by frame tests and FEM analysis. Main conclusions can be drawn as follows:

(1) The semi-rigid steel space frames using end-plate connections exhibit full hysteretic loops under horizontal cyclic load, which indicates that this kind of frames have good energy dissipation capacity.

(2) The semi-rigid steel space frames using end-plate connections exhibit good ductility, which satisfies the interstory drift limit for frame structures in strong earthquakes specified in the seismic design code of China.

(3) Stress and deformation amplitudes at joint-panels are smaller than those at column base and beam ends and plastic hinge finally developed at the beam ends, which indicates that this kind of frames satisfy the design principle of "strong column weak beam and strong joint weak component".

(4) Semi-rigid steel space frames using end-plate connections have basically similar seismic performance in both strong and weak axis directions. However, the lateral stiffness in the weak axis stiffness is smaller. So, it is recommended braces be provided in the weak axis direction.

(5) The FEM analysis results show good agreement with the test results in terms of failure modes and P- $\Delta$ relationship, which demonstrates the validity of the FEM models.

\section{CONFLICT OF INTEREST}

The author(s) confirm that this article content has no conflicts of interest.

\section{ACKNOWLEDGEMENT}

None declared.

\section{REFERENCES}

[1] D.K. Miller, "Lessons Learned from the Northridge Earthquake", Eng. Struct., vol. 20, pp. 249-260, 1998.

[2] S.A. Mahin, "Lessons from Damage to Steel Buildings during the Northridge Earthquake", Eng. Struct., vol.2, pp. 261-270, 1998.

[3] J.C. Anderson, J. Duan, Y. Xiao, and P. Maranian, "Cyclic testing of moment connections upgraded with weld overlays", J. Struct. Eng., vol. 4, pp. 509-516, 2002.

[4] J. Shen, and A. Astaneh-Asl, "Hysteretic Model of Bolted-Angle Connections", J. Construct. Steel Res., vol. 54, pp. 317-343, 2000.

[5] C.G. Matos, and R.H. Dodds, "Probabilistic modeling of weld fracture in steel frame connections, Part II: Seismic loadings", Eng. Struct., vol. 6, pp. 687-705, 2002.

[6] M. Garlock, "Design analysis and experimental behavior of seismic resistant post-tensioned steel moment resisting frames", Ph.D. thesis, Lehigh Univ., Bethlehem, Penn, 2002.

[7] C.W. Roeder, "Connection performance for seismic design of stee moment frames”, J. Struct. Eng., ASCE, vol. 4, pp. 517-525, 2002.

[8] GB50017-2003, Code for design of steel structure [S]. China Building Industry Press: Beijing 2003; pp. 63-73(in Chinese).

[9] W.L. Li, "Behavior of semi-rigid beam-to-column minor axis connections in steel frames", Ph.D. thesis, Xi'an University of Architecture \& Technology, Xi'an, China, 2007.

[10] S. Chen, and G. Du, "Influence of initial imperfection on the behavior of extended bolted end-plate connections for portal frames", J. Construct. Steel Res., vol. 63, pp. s211-s220, 2007.

[11] A.S. Elnashai, and L. Di-Sarno, "Fundamentals of Earthquake Engineering”, John Wiley \& Sons, Ltd: US, pp. 85-88, 2008.

[12] GB50011-2001. Code for seismic design of buildings [S]. China Architecture \& Building Press: Beijing; 2001 (in Chinese). 